\title{
TURISMO E EDUCAÇÃO: TURISMO NOS ANOS INICIAIS DO ENSINO FUNDAMENTAL EM ESCOLAS DO MUNICÍPIO DE FORTALEZA NO ESTADO DO CEARÁ
}

\author{
TOURISM AND EDUCATION: TOURISM IN THE INITIAL YEARS OF ELEMENTARY EDUCATION IN \\ SCHOOLS OF THE MUNICIPALITY OF FORTALEZA IN THE STATE OF CEARÁ
}

\section{TURISMO Y EDUCACIÓN: TURISMO EN LOS AÑOS INICIALES DE LA ENSEÑANZA FUNDAMENTAL EN ESCUELAS DEL MUNICIPIO DE FORTALEZA EN EL ESTADO DE CEARÁ}

\begin{abstract}
Marcel Waline de Carvalho Ferraz Fernandes
Professor do Magistério do Ensino Básico, Técnico e Tecnológico (EBTT) no Instituto Federal de Educação, Ciência e Tecnologia do Ceará (IFCE), campus Canindé. Mestre em Gestão de Negócios Turísticos (UECE, 2007). Especialista em Dinâmicas Grupais na Empresa e na Escola (UNIFOR, 2000). Bacharel em Turismo (UNIFOR, 1998). Cursa o

Doutorado em Turismo e Hotelaria (UNIVALI, 2014 - 2018) marcelwaline@gmail.com
\end{abstract}

Yára Christina Cesário Pereira

Professora titular da Universidade do Vale do Itajaí (UNIVALI), campus Balneário Camboriú. Pós-Doutora em Educação Ambiental (FURG, 2012). Doutora em Educação (UFSC, 2004). Mestra em Educação (UFSC, 1996). Especialista em Supervisão Educacional (PUC MG, 1991). Graduada em Pedagogia (UNIVALI, 1989). Graduada em Ciências Biológicas (FURB, 1977) yara@univali.br

Data de Submissão: 09/07/2016 Data de Aprovação: 15/07/2017

RESUMO: O estudo defende saídas via a educação para melhor entender o turismo no uso de territórios; uso este que passa, necessariamente, pela gestão. Apresenta sete partes da gestão, dentre estas, ajuíza sobre planejamento turístico, reflete sobre território turístico, busca perceber estratégias de aprendizagem para, desde cedo, o educando compreender o turismo no uso de territórios, tendo em vista o entendimento do pertencimento deste sujeito ao lugar dito turístico. Apresenta pesquisa com abordagem qualitativa, evidenciando material de apoio pedagógico institucional, recursos didáticos, sobre turismo nos anos iniciais do ensino fundamental. De noventa recursos em oito encontrou-se referência a turismo. Há um ensino de turismo muito incipiente, com ausência de discussões sobre a identidade do lugar. Não se percebeu atenção no ensino de turismo com a vida familiar e social, trabalho, lazer ou ciência em algumas escolas do Município de Fortaleza no Estado do Ceará. Constata-se um impasse quando do consentimento do fenômeno do turismo, no planejamento do mesmo e em ações de ordenamento territorial devido ao desinteresse de atores pelo tema turismo. A educação é vista, portanto, como a salvaguarda das propostas de maior sensibilização dos atores do turismo para o entendimento do uso amadurecido do território pelo fenômeno do turismo.

PALAVRAS-CHAVE: Turismo. Planejamento turístico. Ensino de Turismo.

ABSTRACT: The study defends solutions via education for a better understanding of tourism in the use of territories, a use that must go through the management. It presents seven aspects of management, among which it assesses tourism planning, reflects on the tourist territory, and seeks to perceive learning strategies so that the learner can understand tourism in the use of territories from an early age, bearing in mind the subject $\square$ s understanding of belonging to this to-called tourist destination. It presents research with a qualitative approach, evidencing institutional pedagogical support material, as educational resources about tourism in the initial years of elementary education. Out of ninety resources, reference to tourism was found in only eight. Education in tourism is still incipient, with no discussion about the identity of the place. No attention was given to teaching tourism with family and social life, work, leisure or science in some schools in the Municipality of Fortaleza in the State of Ceará. A dilemma was seen regarding the consent of the tourism phenomenon, its planning, and territorial planning actions, due to the lack of interest in the subject of tourism. Education is therefore seen as safeguarding of the proposals of greater awareness of the tourism actors, for a better understanding of mature use of the territory by the tourism phenomenon. 
RESUMEN: Este estudio defiende salidas a través de la educación para entender mejor el turismo en el uso de territorios; este uso pasa, necesariamente, por la gestión. Presenta siete partes de la gestión, entre las cuales, se refiere a la planificación turística, reflexiona sobre el territorio turístico, busca percibir estrategias de aprendizaje para que el educando, desde el principio, comprenda el turismo en el uso de territorios, tomando en cuenta el entendimiento de la pertenencia de este sujeto al lugar turístico. Se realiza una investigación con abordaje cualitativo presentando material de apoyo pedagógico institucional y recursos didácticos sobre turismo en los años iniciales de la enseñanza fundamental. De noventa recursos, en ocho se encontraron referencias al turismo. Hay una enseñanza de turismo muy incipiente, con ausencia de discusiones sobre la identidad del lugar. No se observó atención en la enseñanza de turismo con la vida familiar y social, trabajo, ocio o ciencia en algunas escuelas del Municipio de Fortaleza, Ceará. Se constata impase sobre el consentimiento del fenómeno del turismo, en la planificación del mismo y en acciones de ordenamiento territorial por desinterés de los actores sobre el tema turismo. La educación es vista como salvaguarda de las propuestas de mayor sensibilización de los actores del turismo para el entendimiento del uso maduro del territorio por el fenómeno turístico.

PALABRAS CLAVE: Turismo. Planificación turística. Enseñanza del Turismo.

\section{INTRODUÇÃO}

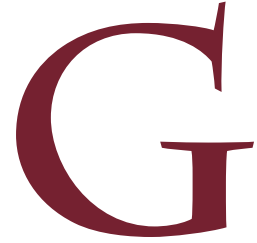

rupos sociais que ascenderam paralelamente com o incremento do setor de transportes impulsionados pela consolidação de uma classe consumidora de produtos turísticos deram origem a diferentes fluxos, promovendo "[...] uma nova ordem no processo de ocupação do espaço, nas mais variadas localidades do mundo verificando-se que há cada vez menos territórios sem turistas" (TELES, 2006, p. 45).

O turismo molda o território de uso a partir de um tipo específico de movimento, decorrente de deslocamentos deste sujeito social: o turista. É justamente a demanda, como elemento definidor, que ajuda a configurar o território turístico, emoldurando-o com o movimento pendular, de vinda e retorno que pode massificar ou não o lugar dito turístico.

O planejamento do fenômeno do turismo é fundamental, pois não se podem ignorar os ranços advindos dos tantos deslocamentos e permanências de turistas em lugares, que passam a sentir os efeitos de uma fragmentação causada pela ordem econômica local-global em questões socioeconômicoculturais e ambientais.

Sustenta Teles (2006, p. 49) que "o território se configura, a partir do espaço e é resultado de uma ação conduzida por um ator sintagmático (ator que realiza um programa) em qualquer nível". Este interventor do espaço que atua 
de forma concreta ou abstrata é um protagonista que territorializa o espaço. $O$ que se precisa perceber é como o surgimento de territórios turísticos que são inventados e produzidos pelos turistas e por organizadores ou desorganizadores do turismo recortam o grande território, deformando-o ou reapresentando-o com outros contornos, quando em vez transfigurados.

O entendimento sobre território é primeiro e necessário e para tal recorrese à disciplina escolar Geografia no contexto dos anos iniciais do Ensino Fundamental em escolas do Município de Fortaleza no Estado do Ceará como um norte teórico que relacione o planejamento e o território para compreender o turismo neste meandro.

Há um impasse quando o consentimento do fenômeno do turismo no que se refere ao planejamento do mesmo e às ações de ordenamento territorial de lugares ditos turísticos, pois nestes há apropriada inquietação quando não se percebe harmonização das técnicas, indicadas, de uso do turismo sustentável durante confrontações com as efetivas ações de gestores nos espaços utilizados pelo turismo. Curiosamente, considerável parte dos sujeitos nativos, moradores ou oriundos dos lugares ditos turísticos, não se comportam de forma colaborativa e respeitosa, na própria origem, para que exista maior índice de utilização sustentável do patrimônio natural e cultural incentivando a conservação e a busca da formação de uma consciência socioambiental.

Busca-se entender, portanto, como a educação formal pode ser um instrumento de otimização da sensibilização dos atores do turismo e, por decorrência, maior entendimento em relação às atitudes e aos comportamentos pertinentes ao uso sustentável do território voltado para o turismo. Uma das funções essenciais da educação escolar é possibilitar a apropriação de conceitos científicos e de diferentes saberes que permeiam as relações entre o destino dos seres humanos, o destino individual, social e histórico, entrelaçados, inseparáveis e complementares na perspectiva da multidimensionalidade humana. Este é o foco do presente artigo: perceber se já existem estratégias de aprendizagem para, desde cedo, o educando compreender o turismo no uso de territórios tendo em vista o entendimento do pertencimento deste sujeito ao lugar. Isto, necessariamente, repercutirá em ações cobradas pelas próprias comunidades sobre a necessidade de um coerente planejamento para o turismo. 


\section{GESTÃO COMPOSTA POR SETE ELEMENTOS}

Os lexicógrafos escreveriam que gestão (do latim, gerentia, de gerere, fazer) é o ato de gerir, gerenciar, administrar. Ter gerência sobre algo é sentirse responsável pela concepção e/ou pelo acompanhamento. Partindo desse entendimento, a gestão pode ser compreendida com o ato de administrar do latim ad (direção, tendência para) e minister (subordinação ou obediência como processo significa planejar, organizar, dirigir, coordenar e controlar organizações e/ou tarefas). Administrar é reger, exercer um cargo ou ofício para que se percebam elementos da gestão.

O conceito de gestão foi adquirindo diferentes definições ao longo da história da humanidade e, nesse movimento, perpassam diferentes interpretações. No entanto, parece existir certo consenso de que gestão é o conjunto de ações/tarefas que buscam garantir a eficiência e a eficácia na execução dos diversos recursos de uma organização a fim de alcançar os objetivos propostos em um planejamento.

O gestor cumpre o papel de gerir, administrar, pesquisar e coletar dados que serão disponibilizados em planilhas, gráficos, relatórios e outros documentos e, ao serem analisados, geram informações sobre o objeto a ser gerido, nesse caso, por exemplo, um lugar turístico. Tais informações, devidamente ordenadas e interpretadas corretamente, deverão gerar conhecimento científico, técnico e normativo para que a gestão, realmente, se desenvolva, por exemplo, no território. $\mathrm{E}$, se necessário for, assim serão aplicadas técnicas de intervenção justificadas por estudos abalizadores que permeiem a legalidade ao se reportarem as normas e as regras regulamentadoras de procedimentos.

Não se consegue compreender a dinâmica da gestão sem se debruçar em conhecer e entender as suas partes componentes. Vale destacar que, no contexto da gestão, o mundo dos negócios exige diferentes direcionamentos e posturas para que se possa encarar os desafios colocados inevitavelmente no e pelo mercado. "Num mundo não linear, apenas as ideias não lineares criarão novas riquezas" (Hamel, 2000, p. 121). 
No âmbito desse trabalho foram consideradas sete as partes da gestão, convencionadas como $\mathrm{PODC}^{3} \mathrm{~S}^{1}$. Tal apresentação remete-se às letras iniciais das sete palavras, em português, lembrando-se que a letra "c" se repetirá três vezes, por serem três distintas palavras: Planejar; Organizar; Dirigir; Comandar; Coordenar; Controlar e Selecionar.

Planejar é o primeiro elemento da gestão e pode ser entendido como projetar, em especial uma ação ou uma determinação. Traçar um planejamento requer fino trato com a preparação de um plano de ação. Tem-se uma sequência coerente para que se perceba a ponderada realização do planejar. $O$ planejamento acontece com a apresentação de um plano e nele há os detalhes da empreitada geral e das divisões necessárias para que cada parte do plano, de fato, se realize. Esse plano é dividido em programas que são âncoras de destaque da ação, agora direcionada para o êxito de acordo com cada parte realizada em separado. Para que cada uma destas partes aconteça, em separado, acelera-se a ação de forma mais esmiuçada com os projetos. Depois que os resultados aparecem, via projetos, e são ajuntados nos programas, conseguese ver o todo realizado no espelho do resultado proposto para o plano.

Um Plano de Desenvolvimento do Turismo de um município, portanto, uma ação do governo municipal, é dividido em programas voltados para frentes de trabalho do turismo no município, por exemplo, ensino de turismo, segurança, saneamento, abastecimento, comunicação, saúde, dentre outros. Idealiza-se, por exemplo, que em meio aos programas que compõem o plano, há o Programa de Ensino de Turismo. Sabe-se que se o plano trabalhará o desenvolvimento do turismo, tem-se que atuar no entendimento, desde cedo em tenra idade, do que é este fenômeno humano intermediando o trato com o turismo como algo que deve incluir e nunca segregar em uma comunidade. Isto como ação da gestão pública municipal. Tal programa será subdividido em projetos direcionados às demandas, já conhecidas, no município. Um destes será o Projeto de Ensino de Turismo para os anos iniciais do Ensino Fundamental que trabalhará ações específicas postas em oficinas lúdicas demonstradoras para um público especial, no caso as crianças.

1 Esta é uma proposição, construída a partir de teorias específicas da administração, percebida em uma dissertação de mestrado [Fernandes (2007)] da Universidade Estadual do Ceará (UECE). 
Vale ressaltar que o planejamento deve ser pensado a curto, médio ou longo prazo, dependendo do volume de ações a serem desenvolvidas e o tempo total disponível, bem como o tempo de acontecimento de cada ação. Planejar é o primeiro passo da gestão que permeará todas as outras partes. Caso não se arquitete, na gestão, o planejamento coerente de um território com base nas peculiaridades do fenômeno envolvido, como o turismo, os prejuízos serão evidentes e galopantes para todos os atores envolvidos.

O segundo elemento da gestão é organizar que sinaliza criar, preparar e dispor convenientemente as partes de uma empreitada ou organismo. Para funcionar e, portanto, estabelecer como base um mote de trabalho os três níveis da organização devem ser lembrados. O arranjo arquitetado de ações e a preparação do terreno para o acontecer acertado ficarão evidentes com o ordenamento nivelar. Então se tem os três níveis da organização conhecidos: estratégico, tático e operacional.

O nível estratégico é o pensar a concepção, a criação. O gestor deve, no nível estratégico, conceber as ideias, as investidas, perceber as melhores ações, sensibilizar-se para os melhores momentos, checar a viabilidade das tarefas e evidenciar o acontecer no tempo corrente. No estratégico, as parcerias certas devem ser bem firmadas e a supervisão será ativada.

O nível tático é o gerenciar a concepção, a criação. O gestor deve acompanhar a implantação das ações. Estas ações são resultantes da ideia ou das ideias concebidas no nível estratégico. A supervisão ativada no nível anterior deverá atuar intensamente durante este gerenciamento do fazer cotidiano.

O nível operacional é o executar a concepção, a criação que neste instante se materializa em resultados reais que podem ser os esperados ou podem ser os sinistros. O gestor conduz o fazer, supervisiona o acontecer, percebe os resultados e corrigi os desvios.

O terceiro elemento da gestão é dirigir, entendido como dar uma direção ou direcionamento, prioritariamente a uma ação na pauta de realizações. O gestor direciona os encaminhamentos necessários para ver acontecer os condicionantes da empreitada. Pode-se, também, neste direcionamento, acontecer os desvios de condutas (dirigir fraudulento), propositais, que maculam o ordenamento, 
por exemplo, de um território turístico, já que há contundentes evidências de outros interesses que se sobrepõem ao que seria considerado sustentável e recomendável no trato com o fenômeno.

O comandante aciona a feitura solicitada por meio da gestão. Comandar é o quarto elemento da gestão e se apresenta com as características de manobrar esforços, recursos para a absorção de resultados, esperados, visando ao funcionamento das engrenagens que alavancam o organismo gerenciado (uma casa, uma empresa ou um município).

O gestor, ao coordenar uma equipe de colaboradores, busca orientar atitudes, encaminhar atribuições de acordo com a classificação das tarefas a serem executadas para uma efetiva supervisão e cobrança de resultados esperados. Lembre-se de que quem coordena duplica a ação de ordenar. Coordenar é, portanto, o quinto elemento da gestão.

O capital intelectual da organização necessita de um olhar cuidadoso dos gestores. O ser humano carece de orientação, incentivo, estimulação e de não controle. Controlar o sexto elemento da gestão remete-se ao entendimento de controle. Controle é a verificação atenta e minuciosa da regularidade de um estado ou de um ato, da validade de uma peça. É o domínio da própria conduta do gestor. Aquele que planeja, organiza, dirige, comanda, coordena e seleciona; controla, ao atuar. Os acertos e os erros resvalarão em todos os níveis da organização (instituição pública ou privada) e em todos os que construíram e contribuíram para a consolidação da estrutura funcional. Todos são responsáveis pelo que foi feito e pelo que se deixou de ser feito em gestão.

Muitas vezes um grupo pluralizado e interdisciplinar é convidado para escolher, mediante conversas, perceber aqueles que podem somar aojá edificado na organização. A seleção acontece num formato criterioso e fundamentado cientificamente. O selecionar é o sétimo e último elemento da gestão.

A gestão se apresenta, neste estudo, como ingrediente que pretende somar ao conveniente e acertado entendimento de como deve ser percebido o território usado pelo turismo. Aqui se defende que a melhor forma de se fazer entender e perpetuar este ensinamento é por meio da educação; seguindo os passos orientadores dos sete elementos da gestão (Drucker, 2002; Kwasnicka, 2007). 


\section{PLANEJAMENTO TURÍSTICO}

O processo de planejamento municipal, estadual, regional, e até nacional, para o desenvolvimento do turismo é, basicamente, uma tarefa coletiva, baseada na conectividade entre as diversas esferas de governo, da sociedade civil organizada e da iniciativa privada. Planejar o turismo é um diálogo constante e um processo de negociação entre atores sociais interessados, assegurando que ações, planos, programas e projetos expressem o consenso da sociedade local, gerando bem-estar social e econômico.

O planejamento deve ser harmônico, sempre lembrando e envolvendo as forças do lugar. A comunidade envolvida precisa entender os benefícios e os malefícios que o turismo pode gerar. Portanto, é necessário envolver todos os atores sociais no planejamento e na implementação das atividades. Cada ação deve ser planejada para que os resultados se transformem em benefícios coletivos, com a comunidade transformando seus atrativos em produtos (bens e serviços) com retorno certo, mediante a articulação, constante de uma tríade necessária que deve ser verificada, insistentemente: equilíbrio ecológico, equidade social e exequibilidade econômica. O envolvimento da comunidade pode e deve acontecer mediante a educação, na escola, no Ensino Fundamental, em projetos vários de esclarecimento.

É importante construir coletivamente o significado, o valor, a relevância social e a pertinência das imagens e dos exemplos ligados ao turismo que forem usados, para que todos possam perceber a realidade do turismo no lugar que é comum, que é de todos. A escola se apresenta como excelente palco para as necessárias revelações.

O planejamento turístico, segundo Hall (2004), está integrado a processos mais amplos a fim de promover metas de melhorias que auxiliem na indicação de quem perde e de quem ganha no turismo favorecendo o desenvolvimento. O mesmo autor lembra valores e princípios do turismo sustentável com metas econômicas, ambientais e de recursos e sociais.

Para o autor em referência (2004), destacam-se como metas econômicas: benefícioseconômicospararesidenteseoutrosinteressados, setoreconomicamente viável, negócios economicamente viáveis. Como metas ambientais e de recursos 
evidenciam-se: manter ou ampliar a biodiversidade, benefícios aos recursos, mínima degradação dos recursos, aceitação dos valores dos recursos, equilíbrio da oferta e da demanda, design adaptável, equidade intergeracional. Por fim, temse como metas sociais: benefícios à comunidade, participação, planejamento, educação, saúde, emprego, satisfação do visitante. Destaca-se nesse artigo a importância da educação (HALL, 2004), para que a médio e longo prazo este planejamento do território turístico consiga ser descrito e interpretado pelos vários usuários, atores do processo, de forma que os benefícios à comunidade, bem elencados por Hall (2004), sejam evidenciados por quem recebe.

A gestão por processos é uma forma de se administrar territorialmente o turismo. Para Anjos (2004, p. 144), "os processos que compõem o planejamento (...) do território turístico precisam ser claramente definidos, determinando entradas e saídas, os atores e os indicadores de processo". Em territórios turísticos, tanto o nativo como o turista estão incluídos no processo de planejamento, conforme Anjos (2004), e este complementa que a compreensão do território turístico deve considerar especificidades tanto dos nativos como dos turistas. Esta divisão socioterritorial indicará "dinâmicas socioculturais (renda, trabalho, lazer, escolaridade, organização e comportamento social) e dinâmicas econômicas (produção, distribuição, consumo e acumulação)" (Anjos, 2004, p. 164).

No planejamento turístico tanto para Hall (2004, p. 33), "metas sociais", como para Anjos (2004, p. 166), "necessidades básicas da população", a educação aparece em ambos os estudos e destacada, precisando ser, no entendimento destes autores, considerada alicerce do fenômeno do turismo, ocupando territórios humanos sem destruí-los ou maculá-los. Já no Ensino Fundamental é possível perceber as necessidades básicas da população que pode ser beneficiada pelo turismo de inclusão e deve rejeitar o turismo de segregação, sendo uma das metas sociais no planejamento turístico a criação de projetos de ensino de turismo, nas escolas, já nos anos iniciais do Ensino Fundamental, portanto, para as crianças bem jovens.

\section{TERRITÓRIO TURÍSTICO}

O território para as sociedades humanas representa uma parcela do espaço identificada pela posse. Na geopolítica, o território é o espaço nacional ou 
área controlada por um Estado-nacional. Também não é apenas a configuração política de um Estado-nacional, mas sim o espaço constituído pela formação social. "Território é a área de vida de uma espécie, seja animal ou vegetal. É o domínio que estes têm sobre porções da superfície terrestre. É a base física e material da paisagem que se expressa numa determinada extensão onde se estabelece alguma forma de fronteira" (Brasil, 1997, p. 156).

Compreender território implica compreender a complexidade da convivência em um mesmo espaço, nem sempre harmônica, da diversidade de tendências, ideias, crenças, sistemas de pensamentos e tradições de diferentes povos e etnias.

Um conjunto de paisagens, contido pelos limites políticos e administrativos de uma cidade, estado ou país, pode ser considerado um território.

"A paisagem, por sua vez, é definida como uma unidade visível, que possui uma identidade visual caracterizada por fatores de ordem social, cultural e natural, contendo espaços e tempos distintos; o passado e o presente" (Brasil, 1997, p. 122).

A paisagem de uma cidade pode ser constituída pelo relevo, a orientação dos rios e córregos, sobre os quais se implantaram suas vias expressas, o conjunto de construções humanas, a distribuição da população que nela vive, o registro das tensões, sucessos e fracassos da história dos indivíduos e grupos que nela se encontram. É nela que estão expressas as marcas da história de uma sociedade, fazendo, assim, da paisagem, uma soma de tempos desiguais, uma combinação de espaços geográficos (Brasil, 1997).

A paisagem é o terreno fértil para as trocas salutares que o fenômeno do turismo pode proporcionar. É o evidenciar de uma interpolação cultural em espaços geográficos distintos. Pertencer a um território e sua paisagem significa fazer deles o seu lugar de vida e estabelecer uma identidade com eles. O estudo do turismo e por sua vez o entendimento do fenômeno do turismo pode proporcionar a identificação da história do lugar e os critérios usados para se conhecer e entender esta história por parte dos visitantes.

Lugar traduz os espaços com os quais os seres humanos têm vínculos mais afetivos e subjetivos que racionais e objetivos: uma praça onde se brinca 
desde menino, a janela onde se vê a rua, o alto de uma colina onde se avista a cidade.

"O lugar é onde estão as referências pessoais e o sistema de valores que direcionam as diferentes formas de perceber e constituir a paisagem e o espaço geográfico" (Brasil, 1997, p. 112).

Espaçogeográfico, paisagem, território elugarestão associadosàforça daimagem muitas vezes malformada, tão explorada pela mídia. Valores a serem incorporados e posturas a serem adotadas são trazidos à tona pela mídia, confundindo no imaginário aquela paisagem que é real e a que se deseja como ideal. A tarefa de impor e inculcar um modelo de mundo por meio da imagem massificante não é algo que possa ser considerado laborioso e glorioso; no turismo.

No momento em que percepções e interpretações subjetivas ou singulares são sobrepostas por outras padronizadas e pretensamente universais, pode-se ter prejuízos significativos na paisagem, já que o lado afetivo e subjetivo que constitui os lugares constituidores de paisagens pode ser maculado pelo rolo compressor do oportunismo econômico. Assim explica-se a transfiguração e as verdadeiras mutações em territórios utilizados, maquiados, alterados, maculados pelo turismo de exclusão.

A Geografia como ciência está a decodificar as imagens presentes no cotidiano, impressas e expressas nas paisagens e em suas representações, numa reflexão direta e imediata sobre o espaço geográfico e o lugar.

O espaço geográfico é o objeto central de estudos da Geografia e é apresentado por meio de categorias fundamentais, que também são chamadas de categorias de análise. As categorias de análise sintetizam aspectos da organização espacial e possibilitam a interpretação dos fenômenos (como o turismo), que os constituem em múltiplos espaços e tempos (Brasil, 1997). São, então, as categorias de análise da Geografia: o território, a paisagem e o lugar.

Como reconhecer o lugar turístico sem as características identificatórias do lugar geográfico com as nuanças históricas? Com o ensino de turismo nos anos iniciais do Ensino Fundamental pode já iniciar de forma bem sutil e presente um estudo para que se compreenda como se estabelecem as relações locais 
com as universais, como o contexto mais próximo contém e está contido em um contexto mais amplo e quais as possibilidades e implicações que essas dimensões possuem (Brasil, 1997). Enfim! É possível instrumentalizar os atores para que saibam como é o turismo naquele lugar dito turístico e se é este o turismo que, de fato, interessa a comunidade circundante.

\section{ENSINO DE TURISMO}

A educação formal como umas das "dinâmicas socioculturais" é intencional e, por isso, exige planejamento. Particularmente, o ensino de turismo nos anos iniciais do Ensino Fundamental atende os pressupostos teórico-metodológicos dos Parâmetros Curriculares Nacionais (PCN, 1997) para o Ensino Fundamental como um dos temas considerados de relevância social, cuja compreensão, por parte dos aprendizes, se mostra essencial para sua formação como cidadão, entendido como aquele que sabe argumentar as escolhas que lhe foram dadas ou negadas no lugar (local-global) de sua existência. Esse olhar possibilita perceber a articulação entre educação e desenvolvimento.

Segundo Coriolano (2003), não se pode perceber desenvolvimento de um lugar somente com os dados e as informações estatísticas que a economia tão arduamente insiste em exibir. Desenvolvimento local difere, muito, de crescimento econômico local, pois só há desenvolvimento quando este atinge a sociedade, resolvendo seus problemas básicos. O crescimento econômico concentra riqueza, sempre nas mãos de pequenos grupos; quando em vez grupos de outros lugares, o que leva à segregação dos espaços e à separação dos seres humanos.

Toda e qualquer mudança e habilitação do homem passam pela educação. Assim qualquer tentativa de desenvolvimento implica preparar o homem, reconduzi-lo ao seu devido lugar, o protagonista do processo de desenvolvimento. Essa preparação se faz com educação, que é a base necessária a todo desenvolvimento [...] equitativo e humano. (Coriolano, 2003, p. 31).

Para que haja desenvolvimento a partir dessas concepções é necessário saber aprender e identificar, para ser investigado, o que é de fato significativo para 
o desenvolvimento integral do ser humano. O que foi aprendido no contexto escolar precisa repercutir no desenvolvimento de uma comunidade e propagarse no desenvolvimento de uma sociedade. Essa é a função social da educação escolar: ser uma ferramenta de inclusão dos sujeitos no seu lugar; este turístico se assim for.

Apresenta-se como prioridade para qualquer gestor proteger um lugar, seja ele turístico ou não de falaciosos investimentos públicos e privados que não estejam em sintonia com a dinâmica produtiva e organizativa dos seres humanos deste lugar. Há a necessidade de que se perceba a inserção das comunidades no rol produtivo e o resgate dos valores culturais como pilares que sustentam a ideia de um desenvolvimento local quando se pensa em turismo como fenômeno facilitador no processo de inclusão social e econômica.

Estudar o fenômeno do turismo como um recorte econômico é impossibilitar aprender o sentido complexo do fenômeno na percepção do global com a participação de outras disciplinas. Passa necessariamente pela Educação Básica o esclarecimento, o conhecimento e, em alguns momentos, o reconhecimento do que deve ser ensinado e aprendido sobre temas dos mais variados, para que de fato se tenha uma atividade justa, saudável e não transgressora, entre os que acreditam na competência e na habilidade do ser humano para produzir sempre e melhor e viver mais dignamente com os seus pares em um território.

A ação educativa se dá no cenário presente nos lugares turísticos, que deve ser respeitado sem nunca deixar de pensar o local que reage ao global, pois ambos são multidimensionais. As dinâmicas sociais, culturais destes lugares turísticos não costumam ser respeitadas justamente por se pensar muito global e agir no lugar de forma também global. O habitante do lugar que não tem acesso ao conhecimento deixa de agir local e perde a chance de organizar o espaço; este também turístico.

Nesse sentindo, as atividades curriculares desenvolvidas nos anos iniciais do Ensino Fundamental que contemplem temas e subtemas ligados ao turismo e articulados com os eixos transversais (conceituais do turismo) possibilitam a construção de competências e habilidades que permitam uma leitura de mundo de forma sistêmica, entendendo a comunidade que abraça o fenômeno do turismo. 
Investigar como se ensina e como se aprende sobre o lugar, sobre o povo e suas peculiaridades e como este aprendizado tem uma relação direta com o turismo pode possibilitar estudos abalizados e reflexivos sobre a construção de teorias que alicerçam empreitadas para a definitiva e pensada inserção não, necessariamente, de uma disciplina de turismo, mas de um estudo que busque os possíveis pontos de convergência entre as várias áreas e sua abordagem conjunta, proporcionando uma relação epistemológica e interdisciplinar entre os componentes curriculares. No Ensino Fundamental a transversalidade proporciona ao aprendiz perceber seu lugar como seu, como múltiplo, porque é diferente, como real e turístico, também, pois o aproximaria dos fenômenos naturais e sociais do lugar, constituidores de um território por excelência humano que pode ser receptor do fenômeno do turismo.

O aprendizado de conceitos essenciais sobre turismo pode fomentar a criação e o uso de interfaces produtivas com as diversas linguagens textuais, estratégias de aprendizagem e dinâmicas, tais como: a contação de histórias do lugar presente e de lugares do passado; os jogos que favorecem o conhecimento e o reconhecimento do espaço (o geográfico); os cenários artísticos de diferentes paisagens de forma a fornecer ao aprendiz um repertório de ideia que alicerce fortes e variados argumentos sobre o turismo que é desejado e o que é repudiado na comunidade.

A diversidade percebida explica o desejo pelo lugar distante ou não distante, mas diferente. A vontade de viajar para conhecer a diversidade de lugares e culturas pode ser trabalhada por meio de simulações (jogos e brincadeiras) que permitem ao aprendiz compreender os deslocamentos humanos para novos espaços em busca de novas histórias com novas articulações sobre feições sociais e culturais; sejam fatos, sujeitos ou tempos históricos. É algo muito rico; entender o ser humano e o turismo no uso planejado de territórios que acolhem o então fenômeno do turismo.

No processo de ensinar e aprender questões relacionadas ao turismo, podem ser usadas a observação e a descrição de procedimentos, no artifício do conhecimento, uma vez que o turismo pode ser visual, tátil e experimental. O profissional de turismo, quando elabora um roteiro turístico, por exemplo, 
sabe destas características a serem desvendadas e essa experiência pode ser levada à sala de aula já nos anos iniciais do Ensino Fundamental, propiciando ao estudante a capacidade de realizar levantamentos das características visíveis, táteis e sensíveis para uma aplicação turística e educativa.

Acreditando que o turismo abarca a multidimensionalidade do devir das realidades humanas é que se pode propor uma (re)organização do saber com o (re)agrupamento de disciplinas escolares que compõem a matriz curricular dos anos iniciais do Ensino Fundamental com o turismo. A Geografia, a História, a Arte, a Matemática, dentre outras disciplinas, abraçando o Turismo, formam um todo complexo apto a conceber a autonomia, a noção de sujeito, a noção de liberdade, o que era impossível de ser feito pela ciência clássica segundo Morin (2005).

A interdependência das diversas ciências reforça a ideia motriz de transversalidade, já que os temas transversais dão sentido social a procedimentos e conceitos próprios de uma área, como a Geografia, ensinada contemplando o turismo. Portuguez (2001, p. 127) propõe:

[...] uma abordagem do turismo dentro de uma perspectiva transdisciplinar, para evitar o direcionamento das reflexões desse fenômeno por um único profissional e para impedir que um tema digno de ser abordado nas escolas se transforme em uma desagradável cobrança de notas e presenças, que certamente estimularia o desinteresse dos discentes.

O recorte da realidade em elementos separados fragmenta os contextos, as globalizações e as complexidades. Portuguez (2001, p. 122) destaca:

[...] se até o momento planejar o turismo significou obter vantagens financeiras e agradar ao turista, é chegada a hora de repensar o que se entende por desenvolvimento, visto que essa atividade se mostra como um fenômeno que a cada dia se reverte de novas complexidades e remodela mais e mais os espaços onde se processa; infelizmente poucos autores de obras didáticas se deram conta desse fato.

O fenômeno do turismo estudado e entendido como um fenômeno complexo que inclui a singularidade na diversidade instrumentaliza os sujeitos a participarem efetivamente das decisões que harmonizem o 
entendimento entre diferentes culturas, diversos saberes associando o fazer, o saber-fazer, o agir, o apreciar e o contextualizar no universo das várias disciplinas escolares a apropriação dos elementos que compõem o fenômeno do turismo.

\section{O ENSINO DE TURISMO NOS ANOS INICIAS DO ENSINO FUNDAMENTAL}

O estudo de turismo é complexo (por ser multidisciplinar) e ao mesmo tempo lúdico (por ser mítico), instigante, e permite a inserção de tópicos específicos para interpretação em vários momentos da aprendizagem de diferentes disciplinas escolares: Português, Matemática, Ciências, História, Geografia, Arte, Educação Física, Filosofia e idiomas; para citar algumas.

A abordagem dos saberes parte do conhecimento que os aprendizes trazem do seu grupo social, portanto é ponderosa a necessidade de se repensar a organização do tempo escolar, acompanhando as inquietações dos aprendizes, sobre o que se tem aprendido com um currículo que fragmenta a realidade, seus espaços concretos, seus tempos vividos e seus sonhos perdidos.

No Brasil a Lei n 9394, de 20 de dezembro de 1996, Lei de Diretrizes e Bases da Educação Nacional (LDBEN), no artigo 32 (Carneiro, 2002), destaca dentre os pontos que constituem o objetivo de parte do Ensino Básico o fortalecimento dos vínculos de família, dos laços de solidariedade humana e de tolerância recíproca em que se assenta a vida social. Aqui se lembra de que o turismo tem como proposta, numa perspectiva humana inicial, unir os povos por meio das diversas culturas por conta da diversidade das mesmas. Tal união de culturas possibilita entender o turismo no uso de territórios sabendo que tal uso passa, necessariamente, por um coerente planejamento.

Propostas pedagógicas que fomentem a formação de sujeitos, como seres íntegros, que aprendem a ser e a conviver consigo mesmos, com os demais e com o meio ambiente (natural e cultural) de maneira articulada e gradual devem buscar a interação entre as diversas áreas de conhecimento e aspectos 
da vida cidadã com conteúdos básicos para a constituição de conhecimentos e valores. Precisa-se pensar e falar em múltiplas formas de diálogo e interação permeando todo um trabalho pedagógico, brincando, rindo, apoiando, acolhendo, estabelecendo limites com energia e sensibilidade, consolando, observando sempre, desafiando a curiosidade e a criatividade sem ter medo de inserir o novo, o não usual, o não tradicional.

Os aprendizes apresentam grandes possibilidades de simbolizar e compreender o mundo, estruturando seu pensamento e fazendo uso de múltiplas linguagens. Esse desenvolvimento possibilita a elas participarem de jogos que envolvem regras e se apropriar de conhecimentos, valores e práticas sociais construídos na cultura (Brasil, 2005).

Em contato com diferentes formas de representação e sendo desafiada a delas fazer uso, a criança vai descobrindo e, progressivamente, aprendendo a usar as múltiplas linguagens: gestual, corporal, plástica, oral, escrita, musical e, sobretudo, aquela que lhe é mais peculiar e específica, a linguagem do faz de conta, ou seja, do brincar. Sua relação com o outro, consigo mesma e com diferentes objetos da natureza e da cultura que a circundam é mediada por essas formas de expressão e comunicação. O desenvolvimento dessas linguagens não ocorre apenas no interior de uma instituição educativa, sendo, muitas vezes, vivenciado no próprio ambiente doméstico com falas cotidianas como: passeio, lazer, viagem, visitante, turismo e turista.

Entender turismo como um fenômeno social integrador, mobilizador e de inclusão é compreendê-lo, também, como um fenômeno econômico e propagador de um desenvolvimento interessante para todos, principalmente para os conhecedores do lugar, dito turístico.

Em um estudo pluralizado como é a vertente do turismo muitos interesses confusos e alheios aos dos habitantes do lugar afloram por meio de grandes instrumentos como solução; solução desgarrada da realidade local, com aspecto de global, que aparecem para problemas sociais previamente identificados com características locais, portanto, particulares. Cabe saber, em investigação, até que ponto o entendimento, o conhecimento sobre turismo está ajudando na feitura do tecido de soluções factuais para o lugar turístico. 


\section{MATERIAL DIDÁTICO SOBRE TURISMO NOS ANOS INICIAIS DO ENSINO FUNDAMENTAL}

As discussões aqui apresentadas resultam resultados de uma pesquisa de abordagem qualitativa, do tipo exploratória e descritiva em que inicialmente se realizou o levantamento bibliográfico sobre os recursos didáticos utilizados pelos aprendizes em escolas do Município de Fortaleza no Estado do Ceará. De posse dos livros e outros, foi realizada uma leitura minuciosa para identificar os aspectos relativos ao assunto turismo (presença ou ausência) de forma explícita ou implícita.

O método em questão, usado para o efetivo prosseguimento da pesquisa, foi o que comparou notas realizadas a partir de leituras com o observado em campo, ou seja, em escolas públicas e privadas, nas privadas, as que desejam participar, quando a princípio se projetou um referencial de conduta para o contato com o objeto principal de pesquisa no ambiente real: o material utilizado nos anos iniciais do Ensino Fundamental que pudesse contemplar o ensino de turismo. Anotações realizadas em um borrão de campo possibilitaram o esclarecimento de aspectos relativos à temática comparando-os com os conteúdos dos livros didáticos analisados.

Além desses procedimentos, foram realizadas observações com o constante apontamento de dados, gerando informações postas no Diário de Campo do Pesquisador (DCP) frente ao percebido quando do contato com os recursos didáticos (livros, coleções, compêndios e material de apoio pedagógico institucional tanto da gestão pública como da gestão privada).

As técnicas usadas foram: levantamento de dados (coleta do material); técnica de preparação de dados (descrição e redução do material, de fato, necessário); técnica de avaliação de dados (interpretação do material coletado, observado de descrito), tendo em vista perceber e compreender quais conteúdos programáticos distribuídos em diferentes disciplinas eram desenvolvidos em escolas públicas e em escolas privadas fortalezenses.

A investigação teve como Unidade Geográfica de Análise o Município de Fortaleza no Estado do Ceará e possuiu como Unidade Temporal de Análise o período compreendido entre agosto de 2005 e agosto de 2006. 
Com as escolas públicas voltou-se para o trabalho desenvolvido junto aos anos iniciais do Ensino Fundamental pela Secretaria Municipal de Educação e Assistência Social (SEDAS) do Governo do Município de Fortaleza no Estado do Ceará e, da mesma forma, para o trabalho desenvolvido junto aos anos iniciais do Ensino Fundamental pela Secretaria da Educação Básica (SEDUC) do Governo do Estado do Ceará. Este trabalho de coleta de dados e informações foi, plenamente, possível e sem atropelos, devido aos vários acordos de cooperação e convênios entre ambos governos e a Universidade Estadual do Ceará (UECE), vínculo de um dos pesquisadores, autor deste artigo. Sabendo que o Ensino Fundamental existe e é de responsabilidade tanto dos governos municipal e estadual, coletou-se material de apoio pedagógico institucional da gestão pública de ambas as esferas governamentais. Os dados adquiridos a partir da observação, passadas para o Diário de Campo do Pesquisador, como informações principais para a construção do ordenamento do material final, foram descritos e interpretados. O trabalho de observação aconteceu com o material de apoio pedagógico institucional utilizado nas escolas públicas; tanto nas escolas municipais como nas escolas estaduais do Município de Fortaleza, no Estado do Ceará, Nordeste do Brasil.

Para as escolas privadas que trabalhavam com os anos iniciais do Ensino Fundamental, consultou-se a Câmara de Educação Básica (CEB) do Conselho de Educação do Ceará (CEC) sobre a aquisição e uso do livro didático para o Estado.

Passou-se, então, a identificar livros ou coleções indicados e usados pelas escolas privadas, mais uma vez indicadas, as que desejaram participar (tendo em vista que não é possível obrigar as gestões de escolas privadas a participar de uma pesquisa institucional acadêmica pública). A identificação dos livros foi realizada via listagem de livros didáticos, estes adotados por algumas escolas privadas, feita em várias livrarias do Município de Fortaleza no Estado do Ceará. A intenção da identificação dos livros era de se construir o ordenamento do material final descrito e interpretado por ter surgido com a pesquisa.

Foram observados 90 (noventa) recursos didáticos (recursos diversos, em especial livros dentre coleções), incluindo material de apoio pedagógico institucional da gestão pública (municipal e estadual) e em somente 8 (oito) 
ISSN: 1983-7151

peças encontrou-se alguma referência a turismo. Nos outros 82 (oitenta e duas) recursos didáticos não se encontrou nenhuma menção ao assunto turismo, 0 tema ou assunto desejado.

No material de apoio pedagógico institucional das gestões públicas, tanto municipal como estadual, nada foi identificado como relevante para o estudo, o que já levou a perceber o não interesse em trabalhar turismo como umas das questões sociais urgentes, sob a forma de tema transversal. $O$ ensino de turismo nos anos iniciais do Ensino Fundamental integra, no entendimento destes pesquisadores, o rol de temas considerados de relevância social, cuja apropriação por parte dos aprendizes se mostra como um dos elementos essenciais para sua formação como cidadãos e, consequentemente, o efetivo desenvolvimento de um lugar. Talvez as gestões públicas indicadas, municipal e estadual, na época do estudo (2005 a 2007), lembrando que esta pesquisa já foi concluída, não tivessem conhecimento sobre os temas considerados prioritários na formação de crianças. É de bom-tom ponderar que este era o cenário na época do estudo, da pesquisa. Não se pode confundir a pesquisa realizada no tempo dela, naquele período com o artigo, de agora, hoje apresentado. Aqui se escreve sobre algo do passado, no presente, já cabendo, no entendimento destes autores, hoje, uma reedição da pesquisa então realizada para que se possa perceber o cenário com o novo estudo.

Nos livros de história não foram observadas discussões sobre turismo e sim sobre lazer, em momentos textuais que se reportavam ao lazer dos antepassados, dos avós; um lazer praticado na modernidade e comparado ao lazer praticado na contemporaneidade pelas crianças. Já nos livros de História e Geografia, uma peça única para ambas as disciplinas, encontrou-se em tópicos dedicados ao lazer a divisão oportuna para o assunto turismo em uma apresentação bastante sutil. Nos livros de Geografia teve-se, de forma mais efetiva, o assunto lazer e, em especial, o turismo sendo evidenciado algumas vezes e apresentado separadamente. Em outras disciplinas, lamentavelmente, nada foi encontrado sobre o turismo que pudesse ser indício de interesse das gestões em explorar o tema, por exemplo, em letramentos e alfabetização ou em alfabetização matemática. De fato, situando para o hoje, somente em ciências humanas e da natureza encontrou-se algo de interesse. 
Olhou-se detalhadamente as referidas obras (material de apoio pedagógico institucional ou livros de todas as disciplinas dos anos iniciais do Ensino Fundamental nas escolas públicas e privadas) buscando desenhos, figuras, fotografias, gravuras, mapas, croquis ou outra imagem que se remetesse a algo sobre turismo.

Em alguns recursos didáticos foi possível perceber que o(s) autor(es) disponibilizava(m), para os professores, notas explicativas e orientações para o uso da obra. Buscou-se identificar nestas notas ou textos elucidativos algum trecho que mencionasse turismo, mesmo que relacionado com o ensino da História e/ou com o ensino da Geografia.

Em todas os 90 recursos didáticos, quando existia sumário, este foi criteriosamente avaliado, pois nesta parte da obra já é possível perceber se há interesse pelo tema turismo, seja no formato de um texto complementar, como componente de item apresentado como subitem; seja figurando como item e destacado em uma das unidades de trabalho da obra, ou mesmo abrindo capítulo constituindo parte relevante da unidade ou da obra propriamente dita.

Após análise das obras na busca sobre o que já era ensinado ou poderia ser ensinado sobre turismo nos anos iniciais do Ensino Fundamental constatou-se:

1) a relação das manifestações e dos usos das tradições e populares do lugar com o turismo ou qualquer tipo de associação deste com a cultura não foi percebida;

2) um descuido com conceitos essenciais sobre fenômenos, processos, sistemas e operações, principalmente a fenomenologia dos acontecimentos locais como o turismo, quando da elaboração de estratégias, na apresentação das disciplinas;

3) ausência de discussões sobre a identidade do lugar, do bairro, da rua;

4) não se percebeu diretamente uma atenção no tocante à inserção do ensino de turismo relacionando a vida familiar e social ao trabalho, ao lazer ou à ciência e à tecnologia. Houve um distanciamento do que recomenda as Diretrizes Curriculares Nacionais (1997) que é aproximar a vida cidadã das áreas do conhecimento; 
5) aliar a cultura do lugar a tópicos regionais e locais muito enriqueceria a propagação do saber. Neste ponto o turismo, como uma das ditas questões sociais urgentes, sob a forma de tema transversal poderia ter sido lembrado como um tópico local, evidenciando o Município de Fortaleza, Estado do Ceará, na escolha para o trabalho com os aprendizes; o que não aconteceu;

6) havia o ensino de turismo inserido na matriz curricular dos anos iniciais do Ensino Fundamental em algumas escolas, no caso, apenas as privadas do Município de Fortaleza no Estado do Ceará, contudo, na época, ainda, de forma muito incipiente;

7) não foi possível delinear um tipo de ensino de turismo nos anos iniciais do Ensino Fundamental;

8) não se identificaram disciplinas que recebem o nome turismo nos anos iniciais do Ensino Fundamental;

9) não havia um conteúdo programático previsto e cuidadosamente escolhido que trabalhe questões múltiplas sobre turismo nos anos iniciais do Ensino Fundamental.

Segundo Morin (2005), a necessidade de uma reforma de pensamento é essencial para mudança de atitude e isto vem ao encontro do que de forma incipiente pode-se inferir como resultado da pesquisa; não se pode reformar a instituição sem ter previamente reformado os espíritos e as mentes, e não se pode reformá-los se as instituições não estiverem abertas à reforma também.

Nesse contexto, a escola vem sendo desafiada a mudar a lógica da construção do conhecimento, uma vez que as disciplinas fechadas não propiciam a religação de diferentes saberes para o entendimento da multidimensionalidade dos problemas socioeconômico-culturais do mundo contemporâneo. Uma das vocações essenciais da educação é possibilitar a leitura e a compreensão do destino multifacetado do humano: o destino da espécie humana, o destino individual, o destino social, o destino histórico, todos entrelaçados e inseparáveis, conduzindo sempre ao estudo da totalidade humana.

As saídas via a educação formal para melhor entender o turismo no uso de territórios sabendo que tal uso passa, necessariamente, por um coerente 
planejamento precisará de algum tempo e amadurecimento para se consolidar e realizar as mudanças necessárias. O currículo nos anos iniciais do Ensino Fundamental é lugar e tempo de acolhida, análise crítica e respeito aos diferentes saberes, diferentes manifestações culturais e diferentes óticas sobre o lugar como fenômeno do turismo. E, nesse movimento, é a oportunidade de abordar temáticas relativas à cultura patrimonial, à educação ambiental, à alteridade, à equidade, à cidadania. $O$ ensino de turismo como prática pedagógica passa a ser elemento estruturante para a formação cidadã.

\section{CONSIDERAÇÕES FINAIS}

Os problemas mundiais socioeconômico-cultural e ambiental agem sobre os processos locais que retroagem por sua vez sobre os processos mundiais. Responder a este desafio, contextualizando-o em escala mundial, quer dizer, globalizando-o, tornou-se algo absolutamente essencial, apesar de sua extrema dificuldade.

Todos os elementos naturais e culturais estão ligados uns aos outros, sendo impossível conhecer as partes sem conhecer o todo, conhecer o todo sem conhecer as partes e a relação entre elas. Tal perspectiva também se percebe entre os elementos que compõem a gestão e entre as disciplinas escolares da matriz curricular dos anos iniciais do Ensino Fundamental.

Quanto mais se têm conhecimentos especializados e limitados, mais se têm ideias globais absolutamente esdrúxulas sobre a política, o amor ou a vida. Portanto no planejamento do lugar, do território utilizado pelo turismo não é diferente.

Uma comunidade local, entendida como um todo também se encontra presente no interior de cada ser humano, pois todos são portadores de uma linguagem e de uma cultura. Essa é uma visão que rompe com os antigos esquemas simplificantes e deve estar presente em toda empreitada que possa macular um todo ou partes de um todo de uma comunidade que arde de necessidade para ter um território descrito e organizado com base nos problemas que realmente interessam os atores do lugar, ao lugar dito, ou determinado a ser, turístico. 
No turismo tais esquemas simplificantes apresentam o fenômeno como uma bandeira de salvação econômica, que se instala em um lugar como uma alternativa globalizante, estúpida, que se opõe aos conhecimentos particulares, locais, e pelo fato de não haver ligações entre o global e o local a empreitada torna-se oca, vaga, discrepante; impossibilitando, assim, um esperado ordenamento do território, das paisagens e dos lugares múltiplos, sendo estes turísticos.

Despossuído de um pensamento argumentativo, tanto quanto qualquer outro cidadão, o indivíduo do lugar turístico defronta-se com um conhecimento posto pela força de quem detém o poder econômico e, dessa forma, torna-se vulnerável frente às escolhas que terá que fazer em relação à sua vida pessoal e profissional. O que resta é a ignorância e a cegueira.

Há a urgência de uma tomada de consciência política da necessidade de trabalhar em prol de uma produção democrática do saber. Nesse sentido, não há espaço e tempo mais propício do que a escola que, por meio de diálogos entre conhecimento científico, conhecimento escolar e saberes cotidianos, se possa fomentar a participação dos atores envolvidos, libertando-os das amarras sociais.

O desconhecimento do lugar e de suas diferentes modalidades atrativas, aliado ao não entendimento de como o turismo, como estudo, é importante para os seres humanos que são deste lugar e que visitam o lugar que é turístico pode levar a prejuízos como a dificuldade de formação de uma identidade com uma marca própria e o desinteresse, logo cedo, em tenra idade, do que se pode aprender e viver no lugar de origem ou no lugar onde vive, desenvolvendo o sentimento de pertencimento.

Não há desenvolvimento sem inclusão e não se tem inclusão sem a educação; a educação básica prioritariamente. Livrar-se de ideias que se transformam em ações devastadoras em nossos lugares turísticos é o desafio posto. Ensinar e aprender um turismo de inclusão, solidário, comunitário, humano é um dos caminhos.

\section{REFERÊNCIAS}

Anjos, Francisco Antonio dos (2004). Processo de planejamento e gestão de territórios turísticos: uma proposta sistêmica. Tese (Doutorado em Engenharia de Produção) 
Dor: 10.14210/rtva.v19n3.p540-565 - Programa de Pós-Graduação em Engenharia de Produção, Universidade Federal de Santa Catarina, 2004. [Tese disponível no acervo da Biblioteca do campus de Balneário Camboriú da Universidade do Vale do Itajaí (UNIVALI) no Estado de Santa Catarina, Brasil].

Brasil. Ministério da Educação e do Desporto. Conselho Nacional de Educação (2005). Diretrizes Curriculares Nacionais para o Ensino Fundamental. Disponível em: <http://www. portal.mec.gov.br/cne/arquivos/pdf/PCB04_1998.pdf>. Acesso em 09/05/2005.

Brasil. Ministério da Educação e do Desporto. Secretaria de Educação Fundamental (1997). Parâmetros Curriculares Nacionais: história, geografia. Brasília (DF): MEC/SEF, 1997, Volume 5.

Carneiro, Moaci Alves (2002). LDB fácil: leitura crítico-compreensiva: artigo a artigo. Petrópolis (RJ): Vozes.

Coriolano, Luzia Neide Menezes Teixeira (2003). O desenvolvimento voltado às condições humanas e o turismo comunitário. In: CORIOLANO, Luzia Neide Menezes Teixeira; LIMA, Luiz Cruz (Organizadores). Turismo comunitário e responsabilidade socioambiental. Fortaleza: EDUECE.

Drucker, Peter Ferdinand (2002). Introdução à administração. Tradução de Carlos Malferrari. São Paulo: Pioneira Thomson Learning.

Fernandes, Marcel Waline de Carvalho Ferraz (2007). Turismo no Ensino Fundamental I. Dissertação (Mestrado Profissional em Gestão de Negócios Turísticos), Universidade Estadual do Ceará, 2007. [Dissertação disponível no acervo da Biblioteca do campus Itaperi, em Fortaleza, da Universidade Estadual do Ceará (UECE) no Estado do Ceará, Brasil].

Galvão, Izabel (2001). Henri Wallon: uma concepção dialética do desenvolvimento infantil. Petrópolis (RJ): Vozes. (Educação e conhecimento).

Hall, Colin Michael (2004). Planejamento turístico: políticas, processos e relacionamentos. Tradução de Edite Sciulli. São Paulo: Contexto. (Coleção Turismo Contexto).

Hamel, Gary (2000). Liderando a revolução. Rio de Janeiro: Campus.

Kwasnicka, Eunice Lacava (2007). Introdução à administração. São Paulo: Atlas.

Moesch, Marutschka Martini (2000). A produção do saber turístico. São Paulo: Contexto.

Morin, Edgar (2005). Educação e complexidade: os sete saberes e outros ensaios. Organização de Maria da Conceição de Almeida e Edgard de Assis Carvalho. São Paulo: Cortez.

Portuguez, Anderson Pereira (2001). Consumo e espaço: turismo, lazer e outros temas. São Paulo: Roca. 
Teles, Reinaldo Miranda de Sá (2006). A importância do território na prática do planejamento turístico: reflexões acerca do Brasil. In: RUSCHMANN, Doris van de Meene; SOLHA, Karina Toledo (Organizadoras). Planejamento turístico. Barueri (SP): Manole.

\section{CONTRIBUIÇÃO DOS AUTORES NA CONSTRUÇÃO DO ARTIGO}

FERNANDES: Introdução, desenvolvimento teórico, percepção e apuramento de dados, primeira redação do artigo.

PEREIRA: Redação final, revisão, várias correções, fechamento textual.

Tradução do resumo do português para o inglês de Joelma Maria dos Santos Gurgel.

Tradução do resumo do português para o espanhol de Guiomar Ferreira de Almeida. 